\title{
Left bundle branch area pacing for cardiac resynchronisa- tion therapy
}

\author{
L. M. Rademakers
}

Published online: 5 September 2019

(C) The Author(s) 2019

A 72-year-old male patient with complete left bundle branch block (LBBB) with a QRS width of $180 \mathrm{~ms}$ (Fig. 2a), left ventricular ejection fraction of $30 \%$ and New York Heart Association (NYHA) class III heart failure despite optimal medical therapy was scheduled for implantation of a cardiac resynchronisation therapy defibrillator. The right atrial lead was placed in the appendage, while the right ventricular (RV) shock lead was positioned in a septal position. His bundle pacing failed due to a high capture threshold. Subsequently the $4.1 \mathrm{~F}$ lumenless 3830 (SelectSecure, Medtronic, Minneapolis, MN, USA) pacing lead was delivered using the C315HIS (Medtronic) sheath in the left bundle branch area by means of a technique described by Huang et al. ([1]; Fig. 1). The capture threshold was $0.8 \mathrm{~V} / 0.5 \mathrm{~ms}$. Stimulation of the left ventricular (LV) lead with a short atrioventricular (AV) delay $(80 \mathrm{~ms})$ resulted in a typical right bundle branch block with a QRS width of $110 \mathrm{~ms}$. During sequential 'bi-septal' pacing (LV $35 \mathrm{~ms}$ before RV) with an optimal AV delay ( $120 \mathrm{~ms}$ ), the QRS width could be further shortened to $95 \mathrm{~ms}$ (Fig. 2b). The patient responded well to therapy, both in NYHA class (II) and echocardiographic measures.

Conflict of interest L.M. Rademakers declares that he has no competing interests.
Open Access This article is distributed under the terms of the Creative Commons Attribution 4.0 International License (http://creativecommons.org/licenses/by/4.0/), which permits unrestricted use, distribution, and reproduction in any medium, provided you give appropriate credit to the original author(s) and the source, provide a link to the Creative Commons license, and indicate if changes were made.

\section{References}

1. Huang W, Su L, Wu S, et al. A novel pacing strategy with low and stable output: pacing the left bundle branch immediately beyond the conduction block. Can J Cardiol. 2017;33(1736):e1-e3.

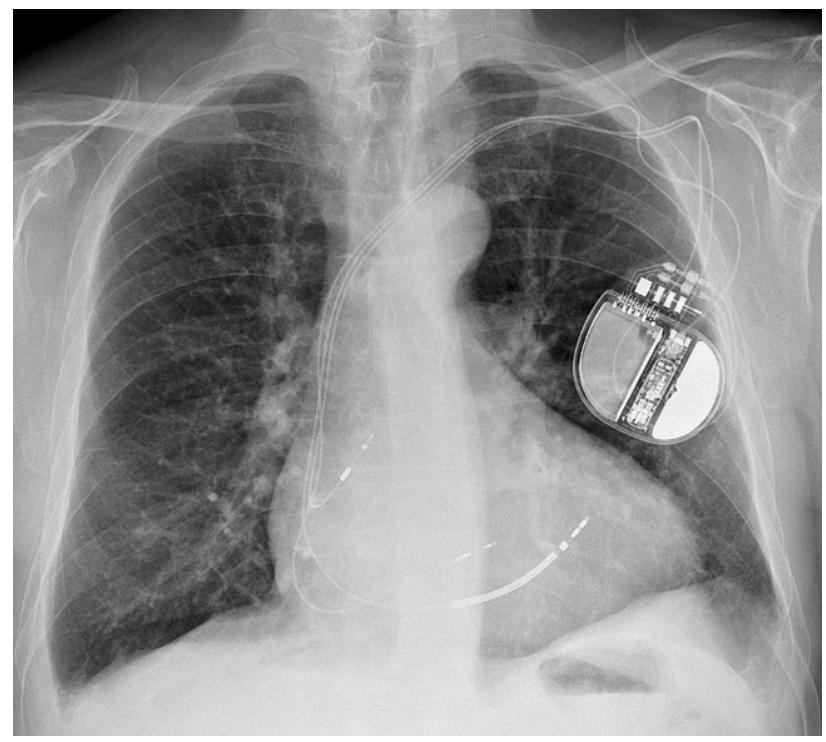

Fig. 1 Chest radiograph in anterior-posterior projection demonstrating final position of right atrial lead, left ventricular lead and right ventricular shock lead 


\title{
Advertisement placed here.
}

\author{
ces bohn \\ CL van loghum
}

Houten 2019 


\title{
Advertisement placed here.
}

\author{
ces bohn \\ CL van loghum
}

Houten 2019 

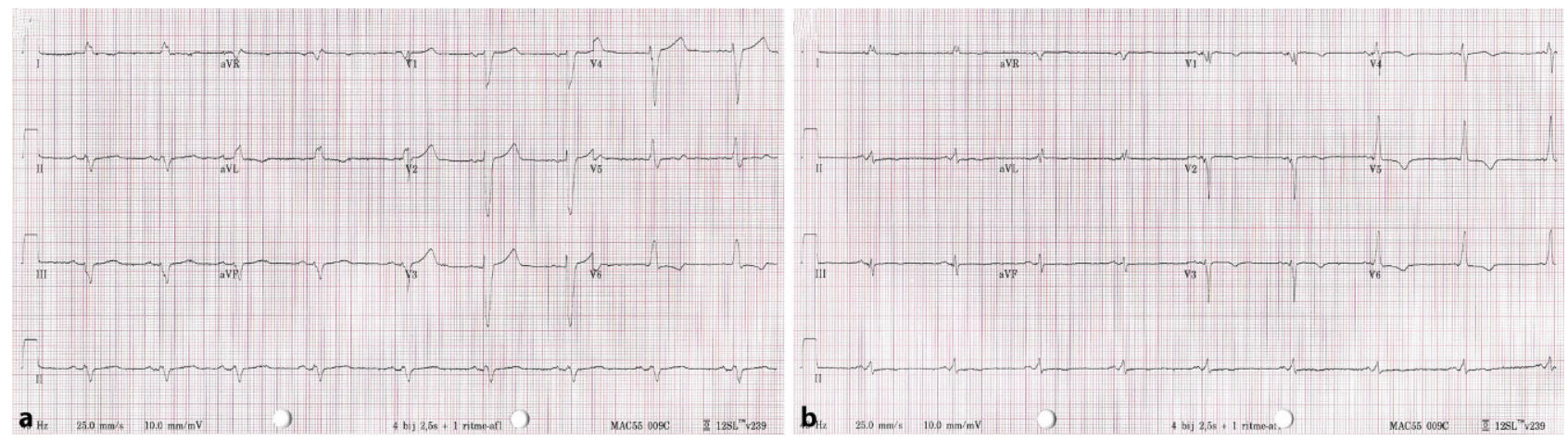

Fig. 2 a Baseline electrocardiogram with complete left bundle branch block and wide QRS complex. b Electrocardiogram during sequential 'bi-septal' pacing with narrow QRS complex 